\title{
Indications for blood transfusions in critical illness
}

\author{
ROBERT BARONICA, DINKO TONKOVIĆ, BOJANA ĐUROVIĆ MRŽLJAK, LOREDANA ĐURIĆ, TIHOMIR KUŠIĆ, KAROLINA REŽEK \\ University Department of Anaesthesiology, Reanimatology and Intensive Care, University Hospital Centre Zagreb, Kišpatićeva 12, 10000 Zagreb, Croatia
}

\author{
Corresponding author: \\ Robert Baronica \\ University Department of Anaesthesiology, Reanimatology and Intensive Care, \\ University Hospital Centre Zagreb, \\ Kišpatićeva 12, 10000 Zagreb, Croatia, \\ Phone: +38512367858 \\ E-mail: rbaronica@gmail.com
}

\section{ABSTRACT}

Transfusion of blood products should improve tissue oxygenation and reduce negative consequences of anaemia. At the same time, adverse effects of transfusion, such as infections, immunologic reactions and mistransfusion, could be deleterious. Most transfusion guidelines suggest looking at the combination of haemoglobin or haematocrit levels in addition to clinical signs in the decision making process for a blood transfusion. The problem with such indications is that the clinical evaluation may be misleading in severely ill patients and haemoglobin levels that impair oxygen delivery cannot be determined easily. Many studies attempted to establish more convenient parameters, such as oxygen saturation from mixed and central venous blood, tissue oxygen extraction and other methods. Although the results from these studies are conflicting, it appears that global oxygenation parameters are a good indicator for a blood transfusion in some categories of critically ill patients.

Key words: haemoglobin concentration, global oxygenation parameters, transfusion, critical illness

\section{INTRODUCTION}

According to the World Health Organisation, anaemia represents a condition of decreased haemoglobin ( $\mathrm{Hgb})$ concentration $(<12 \mathrm{~g} / \mathrm{dL}$ in women and $<13 \mathrm{~g} / \mathrm{dL}$ in men $)$. In a critically ill population, two-thirds of patients match this criteria. The aetiology of anaemia in critical illness relates to haemodilution, bleeding, blood sampling, increased haemolysis, nutritional deficiencies, blunted erythropoietin production, abnormalities in iron metabolism, etc. (1,
2) The ability to develop compensatory mechanisms that would assure metabolic needs, will determine the tolerance of anaemia in each patient. These mechanisms include: blood flow redistribution, increased cardiac output $(\mathrm{CO})$ and increased oxygen extraction ratio (ERO2), among others. (3, 4) Negative effects of anaemia are a result of impaired tissue oxygen delivery (DO2) that may increase the risk of morbidity and mortality in critically ill patients, especially at Hgb levels below 5-6 g/dL. (5) The transfusion of blood products should improve tissue oxygenation and reduce negative consequences of anaemia. At the same time, the adverse effects of transfusion, such as infections, immunologic reactions and mistransfusion, could be deleterious. (4) According to the American Society of Anesthesiologists (ASA), the Society of Thoracic Surgeons (STS) and the Society of Cardiovascular Anesthesiologists (SCA), red blood cells (RBCs) should be administered when DO2 decreases below a critical level or when euvolemic patients develop complications from disturbed tissue oxygenation. $(1,6)$

\section{HAEMOGLOBIN/HAEMATOCRIT THRESHOLDS FOR BLOOD TRANSFU- SIONS IN CRITICAL ILLNESS}

Although the main goal of RBCs transfusions is to improve oxygen delivery and tissue utilisation, a number of intensivists still use Hgb and haematocrit (Htc) levels as an exclusive transfusion trigger. Since a critical Hgb level that impairs DO2 cannot be easily determined, such clinical practice is questionable. (7 - 9) The patient's age, primary diagnosis and clinical symptoms, volume status, aetiology and duration of anaemia, surgery duration, ongoing bleeding, compensatory mechanisms, pulmo- nary, cardiovascular and cerebrovascular comorbidities, and signs of poor end organ perfusion or ischaemia, should significantly affect decisions for transfusion therapy. $(1,3,6,7,9)$ Throughout the years, Hgb/ Htc thresholds for RBCs transfusions have decreased considerably, without adverse effects and worsening clinical outcomes. $(10,11)$ The results of the TRICC study demonstrated that 30 day mortality, frequency of myocardial infarction, acute respiratory distress syndrome (ARDS) and pulmonary oedema were reduced when RBCs were administered at lower Hgb levels or when they were not administered at all. (11) Some other studies of critically ill patients (ABC, CRIT), linked transfusion therapy and the number of transfused units to a higher risk of mortality and prolonged intensive care unit (ICU) and hospital stays. In contrast, similar mortality rates between transfused and nontransfused patients were found in 1,040 septic patients who received a blood transfusion in the observational European SOAP study. In the transfusion group a higher 30-day survival rate was noticed. (12) In the FOCUS study of Carson et al. on high risk elderly patients with underlying cardiovascular disease subjected to the hip surgery, a liberal RBCs transfusion strategy ( $\mathrm{Hgb} \geq 100$ $\mathrm{g} / \mathrm{L})$, in comparison to restrictive strategy $(\mathrm{Hgb} \leq 80 \mathrm{~g} / \mathrm{L}$ or symptomatic anaemia), did not affect mortality or reduce inability to walk independently on a 60-day followup, nor did it affect in-hospital morbidity. The study results did not support the hypotheses that a blood transfusion induces long-term immunosuppression that is severe enough to increase the mortality rate by more than $20-25 \%$. (13) On a study population of 73,067 patients with a non-ST segment elevation myocardial infarction subjected to cardiac catheterisation, Hanna et al. reported that lower Hgb 
concentrations were associated with more extensive coronary artery disease, less use of revascularisation, evidence-based therapies and a higher in-hospital mortality (7\% increase for each $1 \mathrm{~g} / \mathrm{dL}$ decrease in Hgb lower than $15 \mathrm{~g} / \mathrm{dL}$ ). (14) According to the Eastern Association for the Surgery of Trauma and the American College of Critical Care Medicine of the Society of Critical Care Medicine, RBCs transfusions are clearly indicated for the treatment of hemorrhagic shock, particularly in patients who have reached critical DO2. The efficacy of RBCs transfusions in haemodynamically stable trauma and critically ill patients with anaemia has not been demonstrated in most clinical settings. RBCs transfusions should be considered in patients on mechanical ventilation, trauma patients after their initial stabilisation and in patients with stabile cardiac disease below a Hgb level of $7 \mathrm{~g} / \mathrm{dL}$, which is equally effective as transfusions below a Hgb level of $10 \mathrm{~g} / \mathrm{dL}$. In patients with acute coronary syndrome (ACS), RBCs administration may have positive effects at Hgb levels below $8 \mathrm{~g} / \mathrm{dL}$. In septic patients, RBCs transfusions must be assessed individually since optimal transfusion triggers in sepsis are not known and there is no clear evidence that transfusion increases tissue oxygenation. In patients at risk for acute lung injury or ARDS, the administration of RBCs should be avoided. RBCs should not be used as a method of weaning patients from mechanical ventilation. In the absence of acute bleeding, transfusions should be given as single units. (9) The transfusion guidelines from the Croatian Medical Association and the Croatian Society for Quality Improvement in Health Care suggest $\mathrm{Hgb} 7.0 \mathrm{~g} / \mathrm{dL}$ as a level at which transfusion therapy must be started in critically ill patients. (15) The guidelines of the European Society of Anaesthesiology suggest a Hgb concentration of $7.0-9.0 \mathrm{~g} / \mathrm{dL}$ during active perioperative bleeding. (16) ASA guidelines suggest a $\mathrm{Hgb}$ concentration from 6 to $10 \mathrm{~g} / \mathrm{dL}$, depending on a patient's clinical status. Transfusions for patients undergoing cardiopulmonary bypass is indicated at a $\mathrm{Hgb}$ concentration of $6.0 \mathrm{~g} / \mathrm{dL}$. For patients older than 65 and for patients with chronic cardiovascular or respiratory diseases, transfusions are justified at a $\mathrm{Hgb}$ concentration of 7,0 g/dL. For stable patients with a $\mathrm{Hgb}$ concentration between 7 and $10 \mathrm{~g} / \mathrm{dL}$, the benefit of transfusions is unclear. In patients with active bleeding, transfusions are recommended after a blood loss higher than $1,500 \mathrm{~mL}$ or $30 \%$ of blood volume. Rapid blood loss without immediate control warrants a blood transfusion. (1) The American STS and SCA guidelines suggest transfusions in cardiac patients at a Hgb concentration of $6 \mathrm{~g} / \mathrm{dL}$, as this can be lifesaving. Haemoglobin of $7 \mathrm{~g} / \mathrm{dL}$ represents a reasonable transfusion threshold in most cardiac postoperative patients. Transfusions for Hgb levels above $10 \mathrm{~g} / \mathrm{dL}$ is not suggested. (6) Because of insufficient primary compensatory mechanisms, damaged ventricular function and oxygen transport, most guidelines recommend higher $\mathrm{Hgb}$ concentrations as a transfusion indication in patients with ACS. Also, most transfusion guidelines suggest the use of a clinical assessment in combination with the Hgb concentration. The problem with such recommendations is that a clinical evaluation may be misleading in severely ill and unstable patients.

\section{GLOBAL OXYGENATION PARAM- ETERS IN CRITICAL ILLNESS}

Considering the fact that blood loss estimation, intravascular volume and clinical symptoms are not always adequate (and that there is little scientific evidence to point to a specific $\mathrm{Hgb} / \mathrm{Htc}$ level as an optimal transfusion trigger), many studies tried to establish more convenient parameters. Most studies directed their efforts to global oxygenation parameters, such as oxygen saturation from mixed and central venous blood (SVO2, ScVO2), DO2, oxygen consumption (VO2) and $\mathrm{ERO} 2 . \mathrm{SVO} 2$ indicates the relation between global $\mathrm{VO} 2$ and DO2. Tissue dysoxia, indicated by decreased VO2 depending on DO2, usually becomes evident at SVO2 levels of 40-50\%. If $\mathrm{ERO} 2$ is disturbed, tissue dysoxia may be evident at higher SVO2 levels. SVO2 depends on $\mathrm{Hgb}$ concentrations, $\mathrm{CO}, \mathrm{VO} 2$ and arterial oxygen saturations ( $\mathrm{SaO} 2)$. It should be a key factor in determining the amount of blood loss a critically ill patient can tolerate. (17) Studies on animal models with acute, normovolemic haemodilution, demonstrated that a Hgb concentration of $4 \mathrm{~g} / \mathrm{dL}$ represents the level when VO2 starts to decline, which corresponds to SVO2 of $44 \%$ and $\mathrm{ERO} 2$ of $57 \%$. (18, 19) Most investigators used SVO2 and calculated ERO2 as transfusion indicators. Keeping in mind the risks from pulmonary artery catheterisation, the use of these parameters in everyday clinical prac- tice may be difficult. (20-26) Considering the fact that most critically ill patients in medical or surgical ICUs do not have a pulmonary artery catheter inserted, or it is inserted for a short period of time, a question can be raised whether $\mathrm{ScVO} 2$ and $\mathrm{ScVO} 2$ derived ERO2 may be used as relevant transfusion indicators. $\mathrm{SVO} 2$ reflects the relation between $\mathrm{DO} 2$ and $\mathrm{VO} 2$ in the upper and lower parts of the body and the heart. ScVO2 reflects the balance between $\mathrm{DO} 2$ and $\mathrm{VO} 2$ in the cranial part of the body and the brain. Although in normal conditions and healthy individuals SVO2 is higher than $\mathrm{ScVO} 2$ (2-5\%), this relation may change in shock of any aetiology, severe sepsis, cardiac decompensation, head injury, etc. In these conditions (due to a blood flow redistribution in the upper parts of the body, decreased splanchnic and renal circulation and increased ERO2) ScVO2 may outmatch SVO2 by up to $20 \%$. (27-31) The use of individual $\mathrm{ScVO} 2$ and $\mathrm{ERO} 2$ values as transfusion indicators in these conditions is questionable. In the most common situations in the ICU, when $\mathrm{SaO} 2$ is near $100 \%, \mathrm{ERO} 2$ may be calculated from the $\mathrm{SaO} 2$ and $\mathrm{SVO} 2$ difference, without a need for $\mathrm{VO} 2$ and DO2 measurements. (31, 33, 34) When anaemia results in DO2 reduction, ERO2 of $50 \%$ represents an indirect indicator of tissue oxygen deficit and may be used as a transfusion trigger. (24) Studies that compared ScVO2 and SVO2 in various clinical situations have still not provided reliable answers on the question of whether or not both of these parameters can be used for the purpose of triggering transfusion therapy. As a result of blood flow redistribution, regional impairment of tissue oxygenation and microcirculation in critically ill patients, the various outcomes of these studies are often inconclusive. Therapeutic procedures in the ICU (oxygenotherapy, assisted ventilation, administration of fluids, inotropes, anaesthetics, analgetics, sedatives etc.) additionally contribute to a disproportionality between $\mathrm{ScVO} 2$ and SVO2. $(28,29,30)$ Although ScVO2 and SVO2 do not correlate completely, in the 2012 Surviving Sepsis Campaign Guidelines, both of these values are considered equivalent, and targets of $70 \%$ and $65 \%$ respectively are recommended in the beginning of septic resuscitation. (35) In a study by Rivers et al., ScVO2 was used during early goal-directed therapeutic interventions to restore a balance between $\mathrm{DO} 2$ and $\mathrm{VO} 2$ in patients with severe sepsis and 
septic shock. (36) On animals, and later on high risk critical patients, Reinhart et al. demonstrated a good correlation between $\mathrm{ScVO} 2$ and SVO2 in conditions such as bleeding, fluid resuscitation, hypoxia, normoxia and hyperoxia. According to the authors, ScVO2 may confidently predict acute changes in $\mathrm{VO} 2 / \mathrm{DO} 2$ relations, i.e. monitor trends in DO2 and VO2. $(31,37)$ Sekkat et al. and Dueck et al. had similar conclusions on cardiac and neurosurgical patients. They found significant differences in the numerical $\mathrm{ScVO} 2$ and $\mathrm{SVO} 2$ values, but also they found trends between these parameters that correspond to various haemodynamic conditions which can be used in clinical decision making. $(38,39)$ In a study on 53 surgical and medical patients, Chawla et al. concluded that ScVO2 was not a reliable substitute for $\mathrm{SVO} 2$, and that calculating VO2 in this way may cause serious errors. (40) In a study on 20 patients in hemorrhagic or septic shock, Ho et al. demonstrated that changes in ScVO2 and SVO2 do not accompany each other and that this distinction increases when SVO2 falls below $70 \%$. (41) In a study on 20 patients, Lorentzen et al. found that $\mathrm{ScVO} 2$ and SVO2 were not comparable in patients undergoing aortic valve replacement. In patients subjected to coronary artery bypass graft (CABG) procedures, $\mathrm{ScVO} 2$ may be used as a $\mathrm{SVO} 2$ substitute, although absolute values were not completely the same. Lower $\mathrm{SaO} 2(<92 \%)$, reduced Hgb levels and low CO, increased this disproportion. (42) Elsherbeny et al. found that there is poor agreement between $\mathrm{ScVO} 2$ and $\mathrm{SVO} 2$ regardless of type of surgery, changes in $\mathrm{CO}$ and type of pharmacological support. $\mathrm{ScVO} 2$ values above $70 \%$ could reliably predict normal SVO2, but ScVO2 values below 70\% could not reliably predict inadequate SVO2. (43)

\section{GLOBAL OXYGENATION PARAM- ETERS AS INDICATORS FOR BLOOD TRANSFUSION}

In a study by Paone et al. on 100 cardiovascular patients, SVO2 of 55\% was used as a transfusion trigger. The study results showed that blood transfusions were significantly reduced in comparison to the amount of blood that would be transfused if traditional triggers were used. (20) On 60 high risk, surgical, haemodynamically stable patients, Adamczyk et al. assessed the $\mathrm{ScVO} 2$ value for a decision for blood transfusions in comparison to the criteria of the French guidelines for blood transfusions in critically ill patients, which is based on a consensus by the French Society of Intensive Care Medicine (SLRF). The French guidelines suggest administration of RBCs according to Hgb levels and the associated clinical state of the patient $(10 \mathrm{~g} / \mathrm{dL}$ - ACS, $9 \mathrm{~g} / \mathrm{dL}$ - ischemic heart disease, stable heart failure, $8 \mathrm{~g} / \mathrm{dL}>75$ years, severe sepsis, $7 \mathrm{~g} / \mathrm{dL}$ - other critically ill patients). In the study, patients were retrospectively divided into two groups based on ScVO2 values (< or $>70 \%$ ) prior to transfusion therapy. Each group was additionally divided in two subgroups, depending on whether SLRF criteria were matched. Although the transfusions significantly increased $\mathrm{Hgb}$ levels in all patients, ScVO2 was significantly increased only in patients with pretransfusion levels below $70 \%$. Thirteen patients of 20 that were transfused contrary to SLRF recommendations had an $\mathrm{ScVO} 2<70 \%$, and regarding the $\mathrm{VO} 2 / \mathrm{DO} 2$ relationship they seemed to benefit from the blood transfusion. $54.5 \%$ of the patients that received a blood transfusion according to the SRLF criteria had an ScVO2 $\geq 70 \%$, which implies that the $\mathrm{VO} 2 / \mathrm{DO} 2$ relation had been adequate and that the patients were transfused in excess. (21) Considering physiologic and pathophysiologic mechanisms for the oxygen exchange at the cellular and tissue levels, ERO2 could be used as the best indicator for transfusion therapy. $(22-26,44,45)$ A reduction in ERO2 following the administration of RBCs should point out that a blood transfusion was justified. Bashir et al. compared cerebral and peripheral oxygen saturation in patients subjected to autologous blood transfusions during abdominal aortic aneurysm repair. In the post-transfusion group of patients with decreased ERO2, a statistically significant increase in cerebral oxygen saturation, Hgb concentration, oxygen partial pressure and SVO2 was noticed. (44) On an animal model, Wilkerson et al. tried to determine whether global ERO2 reflects disturbed myocardial metabolism during acute, normovolemic anaemia. The left ventricular metabolism (arterial-coronary sinus lactate) was compared to ERO2. The authors concluded that ERO2 could be a valid indicator of myocardial metabolism in anaemia and that significant myocardial lactate production starts when global ERO2 exceeds $50 \%$, which may serve as an indication for a blood transfusion. (22)
On animals subjected to critical left ascending coronary artery stenosis, Levy et al. demonstrated that cardiac failure occurs at higher Htc levels. In the presence of limited coronary vascular reserve, the whole body ERO2 greater than 50\% may serve as a valid indicator of myocardial metabolism in anaemia, and may be a useful guide to transfusion therapy. (23) In the study of Orlov et al. on patients subjected to cardiopulmonary bypass (CPB) procedures, the post-transfusion $\mathrm{ERO} 2$ values did not change in patients with normal pre-transfusion ERO2 values. In patients with elevated pre-transfusion ERO2 values, a significant reduction in ERO2 levels was noticed after the transfusion. The authors concluded that incorporating ERO2 into the decision on transfusion therapy could substantially reduce post-cardiac surgery RBCs transfusions. (24) Seghal et al. tried to determine whether transfusion practices would have been different if an ERO2 $\geq 45 \%$ had been used as a transfusion trigger on patients subjected to $\mathrm{CABG}$ procedures. The authors concluded that the use of ERO2 in transfusion algorithms could reduce allogeneic blood transfusion. (25) In a study by O'Farrell et al. on patients subjected to complex cardiac surgical procedures, a decrease in ERO2 was noticed two hours after the administration of RBCs if the baseline ERO2 was elevated. The study suggests that increased ERO2 may be a better transfusion trigger than decreased Hgb concentrations and that using ERO2 in everyday clinical practice may reduce unnecessary blood transfusions. In the study, $40 \%$ of transfusions would have been avoided if elevated ERO2 was used as the transfusion trigger instead of Hgb concentrations. (26) On 58 patients admitted to the general ICU, Mung'ayi et al. tried to determine the relation between RBCs transfusions and ERO2, using $\mathrm{ScVO} 2$ instead of SVO2. The study showed that blood transfusion did not significantly change ERO2. Changes in Hgb concentrations did not correlate with ERO2 changes following blood transfusions. In patients with a higher APACHE score, a statistically significant relation in the change of ERO2 following blood transfusion was noticed. A subgroup analysis of the patients with pretransfusion ERO2 higher than 0.30 yielded a mean reduction in ERO2 of 0.055 . The study results imply that the majority of patients who were transfused, did not physiologically require $\mathrm{RBCs}$, and did not benefit from the increased oxygen content. The 
authors' comment on the lack of significant changes in the ERO2 was that about $60 \%$ of the patients had a baseline ERO2 below 0.30 . If ERO2 of 0.45 had been the transfusion trigger, then only 3 out of 58 patients would have been transfused. (45) Despite the fact that blood transfusions may improve physiologic and even global oxygenation parameters in critically ill patients, blood circulation to individual organs, regional oxygenation and microvascular perfusion may be significantly impaired. (46) This impairment may be expressed particularly when stored RBCs are used. On an animal model, Tsai et al. compared the effects of fresh and stored RBCs on microvascular perfusion and DO2 after acute isovolemic hemodilution. In comparison to fresh RBCs, stored RBCs reduced microvascular flow and functional capillary density, microvascular oxygen extraction and the tissue oxygen levels. The authors concluded that stored RBCs caused signifi- cantly malperfused and underoxygenated microvasculature, that was not detectable on the systemic level. (47) Possible future 'physiologic' transfusion triggers will be organ-specific, based on impairment of regional tissue oxygenation. Myocardial tissue oxygenation, estimated by electrocardiographic ST-segment changes, cerebral, abdominal and muscle tissue oxygenation estimated by near infrared spectroscopy or in-vivo optical spectroscopy, regional capnography, neuropsychologic and cognitive function tests and other techniques have already been investigated in a number of transfusion therapy studies. $(17,48,49,50)$

\section{CONCLUSION}

Well indicated transfusion therapy will improve patients' clinical outcomes and even save lives. The uncritical administration of blood products will impair patients' primary conditions, cause serious adverse effects and unnecessary financial expenses. Most transfusion guidelines suggest that a combination of $\mathrm{Hgb} / \mathrm{Htc}$ levels and clinical signs should be used in the decision making process for blood transfusions. The problem with such indications is that clinical evaluation may be misleading in severely ill patients, and Hgb levels that impair oxygen utilisation cannot be easily determined. SVO2 and ERO2 are good indicators that show whether a blood transfusion is really necessary. Whenever possible, this is what should be used in everyday clinical practice. In some patients categories in the ICU, ScVO2 and ERO2 derived from $\mathrm{ScVO} 2$ could be used as transfusion indicators, provided that clinicians are familiar with the specific differences between ScVO2 and SVO2 in normal and critically ill patients.

\section{REFERENCES}

1. Practice guidelines for perioperative blood management: an updated report by the American Society of Anesthesiologists Task Force on Perioperative Blood Management. Anesthesiology 2015;122(2):241-275.

2. Corwin HL, Gettinger A, Pearl RG, Fink MP, Levy MM, Abraham E, et al.. The CRIT Study: Anemia and blood transfusion in the critically ill--current clinical practice in the United States. Crit Care Med 2004;32(1):39-52.

3. Van Der Linden P. Transfusion strategy. Eur J Anaesthesiol 2001;18(8):495-498.

4. Marcucci C, Madjdpour C, Spahn DR. Physiology, Benefits and Risks of Red Blood Cell Transfusion. In:Vincent JL, editor. Yearbook of Intensive Care and Emergency Medicine Volume 2005, 1st ed. Verlag Berlin Heidelberg New York: Springer; 2005.p. 505516.

5. Carson JL, Noveck H, Berlin JA, Gould SA. Mortality and morbidity in patients with very low postoperative Hb levels who decline blood transfusion. Transfusion 2002;42(7):812-818.

6. Society of Thoracic Surgeons Blood Conservation Guideline Task Force, Ferraris VA, Brown JR, Despotis GJ, Hammon JW, Reece TB, Saha SP, Song HK, Clough ER; Society of Cardiovascular Anesthesiologists Special Task Force on Blood Transfusion, ShoreLesserson LJ, Goodnough LT, Mazer CD, Shander A, Stafford-Smith M, Waters J; International Consortium for Evidence Based Perfusion, Baker RA, Dickinson TA, FitzGerald DJ, Likosky DS, Shann KG. 2011 update to the Society of Thoracic Surgeons and the Society of Cardiovascular Anesthesiologists blood conservation clinical practice guidelines. Ann Thorac Surg 2011;91(3):944982.

7. Vincent JL, Baron JF, Reinhart K, Gattinoni L, Thijs L, Webb A, et al. Anemia and blood transfusion in critically ill patients. JAMA 2002;288(12):1499-1507.

8. Hajjar LA, Auler Junior JO, Santos L, Galas F. Blood tranfusion in critically ill patients: state of the art. Clinics (Sao Paulo) 2007;62(4):507-524.

9. Napolitano LM, Kurek S, Luchette FA, Corwin HL, Barie PS, Tisherman SA, et al. Clinical practice guideline: red blood cell transfusion in adult trauma and critical care. Crit Care Med 2009;37(12):3124-3157.

10. McIntyre L, Tinmouth AT, Fergusson DA. Blood component transfusion in critically ill patients. Curr Opin Crit Care 2013;19:326333.

11. Hébert PC. Transfusion requirements in critical care (TRICC): a multicentre, randomized, controlled clinical study. Transfusion Requirements in Critical Care Investigators and the Canadian Critical care Trials Group. Br J Anaesth 1998;81 Suppl 1:25-33.

12. Vincent JL, Sakr Y, Sprung C, Harboe S, Damas P, Sepsis Occurrence in Acutely Ill Patients (SOAP) Investigators. Are blood transfusions associated with greater mortality rates? Results of the Sepsis Occurrence in Acutely Ill Patients study. Anesthesiology 2008;108(1):31-9.

13. Carson JL, Sieber F, Cook DR, Hoover DR, Noveck H, Chaitman BR, et al. Liberal versus restrictive blood transfusion strategy: 3-year survival and cause of death results from the FOCUS randomised controlled trial. Lancet 2015;385(9974):1183-1189.

14. Hanna EB, Alexander KP, Chen AY, Roe MT, Funk M, Saucedo JF. Characteristics and in-hospital outcomes of patients with non-ST-segment elevation myocardial infarction undergoing an invasive strategy according to hemoglobin levels. Am J Cardiol 
2013;111(8):1099-1103.

15. Skodlar J, Majerić-Kogler V, Štimac D, Šakić K, Perić M, Balen S, et al. Croatian Medical Association and Croatian Society for Quality Improvement in Health Care transfusion guidelines, 2014.

16. Kozek-Langenecker SA, Afshari A, Albaladejo P, Santullano CA, De Robertis E, Filipescu DC,et al. Management of severe perioperative bleeding: guidelines from the European Society of Anaesthesiology. Eur J Anaesthesiol 2013;30(6):270-382.

17. Vallet B, Robin E, Lebuf G. Venous oxygen saturation as a physiologic transfusion trigger. Criti Care 2010;14(2):213.

18. Trouwborst A, Tenbrinck R, van Woerkens EC. Blood gas analysis of mixed venous blood during normoxic acute isovolemic hemodilution in pigs. Anesth Analg 1990;70:523-529.

19. Räsänen J. Supply-dependent oxygen consumption and mixed venous oxyhemoglobin saturation during isovolemic hemodilution in pigs. Chest 1992;101(4):1121-1124.

20. Paone G, Silverman NA. The paradox of on-bypass transfusion thresholds in blood conservation. Circulation 1997;96(9 Suppl):205-208.

21. Adamczyk S, Robin E, Barreau O, Fleyfel M, Tavernier B, Lebuffe G, Vallet B. Contribution of central venous oxygen saturation in postoperative blood transfusion decision. Ann Fr Anesth Reanim 2009;28(6):522-530.

22. Wilkerson DK, Rosen AL, Gould SA, Sehgal LR, Sehgal HL, Moss GS. Oxygen extraction ratio: a valid indicator of myocardial metabolism in anemia. J Surg Res 1987;42(6):629-634.

23. Levy PS, Chavez RP, Crystal GJ, Kim SJ, Eckel PK, Sehgal LR, et al. Oxygen extraction ratio: a valid indicator of transfusion need in limited coronary vascular reserve? J Trauma 1992;32(6):769-774.

24. Orlov D, O’Farrell R, McCluskey SA, Carroll J, Poonawala H, Hozhabri S, et al. The clinical utility of an index of global oxygenation for guiding red blood cell transfusion in cardiac surgery. Transfusion 2009;49(4):682-688.

25. Sehgal LR, Zebala LP, Takagi I, Curran RD, Votapka TV, Caprini JA. Evaluation of oxygen extraction ratio as a physiologic transfusion trigger in coronary artery bypass graft surgery patients. Transfusion 2001;41(5):591-595.

26. O’Farrell R, Ghannam M, McCluskey M, Beattie S, Karkouti K. Oxygen extraction ratio (OER) and blood transfusion in cardiac surgery. Can J Anaesth June 2006;53(1) Suppl:26342

27. Treacher DF, Leach RM. Oxygen transport-1. Basic principles. BMJ 1998;317(7168):1302-1306.

28. Shepherd SJ, Pearse RM. Role of central and mixed venous oxygen saturation measurement in perioperative care. Anesthesiology 2009;111(3):649-656.

29. Turnaoğlu S, Tuğrul M, Camci E, Cakar N, Akinci O, Ergin P. Clinical applicability of the substitution of mixed venous oxygen saturation with central venous oxygen saturation. J Cardiothorac Vasc Anesth 2001;15(5):574-579.

30. Scheinman MM, Brown MA, Rapaport E. Critical assessment of use of central venous oxygen saturation as a mirror of mixed venous oxygen in severely ill cardiac patients. Circulation 1969;40(2):165-172.

31. Reinhart K, Rudolph T, Bredle DL, Hannemann L, Cain SM. Comparison of central-venous to mixed-venous oxygen saturation during changes in oxygen supply/demand. Chest 1989;95(6):1216-1221.

32. Žaja J. Venous oximetry. Signa Vitae 2007;2(1):6-10.

33. Marino PL. The ICU Book. Fourth ed. Philadelphia: Lippincott Williams \& Wilkins; 2014.

34. Reinhart K, Bloos F. The value of venous oximetry. Curr Opin Crit Care 2005;11(3):259-263.

35. Dellinger RP, Levy MM, Rhodes A, Annane D, Gerlach H, Opal SM, et al; Surviving sepsis campaign: international guidelines for management of severe sepsis and septic shock: 2012. Crit Care Med 2013;41(2):580-637.

36. Rivers E, Nguyen B, Havstad S, Ressler J, Muzzin A, Knoblich B, et al. Early goal-directed therapy in the treatment of severe sepsis and septic shock. N Engl J Med 2001;345:1368-1377.

37. Reinhart K, Kuhn HJ, Hartog C, Bredle DL.Continuous central venous and pulmonary artery oxygen saturation monitoring in the critically ill. Intensive Care Med 2004;30(8):1572-1578.

38. Sekkat H, Sohawon S, Noordally SO. A comparison of mixed and central venous oxygen saturation in patients during and after cardiac surgery. JICS 2009;10(2):99-101.

39. Dueck MH, Klimek M, Appenrodt S, Weigand C, Boerner U. Trends but not individual values of central venous oxygen saturation agree with mixed venous oxygen saturation during varying hemodynamic conditions. Anesthesiology 2005;103(2):249-257.

40. Chawla LS, Zia H, Gutierrez G, Katz NM, Seneff MG, Shah M. Lack of equivalence between central and mixed venous oxygen saturation. Chest 2004;126(6):1891-1896.

41. Ho KM, Harding R, Chamberlain J, Bulsara M. A comparison of central and mixed venous oxygen saturation in circulatory failure. J Cardiothorac Vasc Anesth 2010;24(3):434-439.

42. Lorentzen AG, Lindskov C, Sloth E, Jakobsen CJ. Central venous oxygen saturation cannot replace mixed venous saturation in patients undergoing cardiac surgery. J Cardiothorac Vasc Anesth 2008;22(6):853-857.

43. Elsherbeny A, Belahith M. Agreement between central and mixed venous oxygen saturation following cardiac surgery. J Anesth Clin Res 2014;5:2.

44. Bashir Z, Haynes S, Sandbach P, Calderwood R, McCollum C, Thorniley M. Cerebral oxygen saturation measurements in red cell transfusion. Adv Exp Med Biol 2012;737:51-56.

45. Mung'ayi V, Sharif T, Odaba DS. Blood transfusion and oxygen extraction ratio in patients admitted to the general intensive care unit: A quasi experimental study. Afr J Emerg Med 2014;4(2):66-70.

46. Stowell CP. All politics, and oxygenation, are local: decision making and red blood cell transfusion. Transfusion 2009;4(49):620621. 
47. Tsai AG, Cabrales P, Intaglietta M. Microvascular perfusion upon exchange transfusion with stored red blood cells in normovolemic anemic conditions. Transfusion 2004;44(11):1626-1634.

48. Leung JM, Weiskopf RB, Feiner J, Hopf HW, Kelley S, Viele M et al. Electrocardiographic ST-segment changes during acute, severe isovolemic hemodilution in humans. Anesthesiology 2000;93:1004-1010.

49. Creteur J, Neves AP, Vincent JL. Near-infrared spectroscopy technique to evaluate the effects of red blood cell transfusion on tissue oxygenation. Crit Care 2009;13 (Suppl 5):S11.

50. Vretzakis G, Georgopoulou S, Stamoulis K, Tassoudis V, Mikroulis D, Giannoukas A, et al. Monitoring of brain oxygen saturation (INVOS) in a protocol to direct blood transfusions during cardiac surgery: a prospective randomized clinical trial. J Cardiothorac Surg 2013;8:145. 